\title{
Mixed-source reintroductions lead to outbreeding depression in second-generation descendents of a native North American fish
}

\author{
DAVID D. HUFF, * LOREN M. MILLER ${ }^{*}$ CHRISTOPHER J. CHIZINSKI* and \\ BRUCE VONDRACEK*† \\ *Department of Fisheries, Wildlife and Conservation Biology, University of Minnesota, 1980 Folwell Avenue, 200 Hodson Hall, \\ Saint Paul, MN 55108, USA, +United States Geological Survey, Minnesota Cooperative Fisheries and Wildlife Research Unit
}

\begin{abstract}
Reintroductions are commonly employed to preserve intraspecific biodiversity in fragmented landscapes. However, reintroduced populations are frequently smaller and more geographically isolated than native populations. Mixing genetically, divergent sources are often proposed to attenuate potentially low genetic diversity in reintroduced populations that may result from small effective population sizes. However, a possible negative tradeoff for mixing sources is outbreeding depression in hybrid offspring. We examined the consequences of mixed-source reintroductions on several fitness surrogates at nine slimy sculpin (Cottus cognatus) reintroduction sites in south-east Minnesota. We inferred the relative fitness of each crosstype in the reintroduced populations by comparing their growth rate, length, weight, body condition and persistence in reintroduced populations. Pure strain descendents from a single source population persisted in a greater proportion than expected in the reintroduced populations, whereas all other crosstypes occurred in a lesser proportion. Length, weight and growth rate were lower for second-generation intra-population hybrid descendents than for pure strain and first-generation hybrids. In the predominant pure strain, young-of the-year size was significantly greater than any other crosstype. Our results suggested that differences in fitness surrogates among crosstypes were consistent with disrupted co-adapted gene complexes associated with beneficial adaptations in these reintroduced populations. Future reintroductions may be improved by evaluating the potential for local adaptation in source populations or by avoiding the use of mixed sources by default when information on local adaptations or other genetic characteristics is lacking.
\end{abstract}

Keywords: Cottus, fish conservation, fitness, hybridization, sculpin, translocation

Received 23 July 2010; revision received 21 July 2011; accepted 3 August 2011

\section{Introduction}

Reintroductions, which are intended to re-establish a species within its former range, are a common practice (IUCN 1998; Fischer \& Lindenmayer 2000; Seddon et al. 2007) and are integral to a high proportion of recovery plans for imperiled fishes in North America (Williams et al. 1988; George et al. 2009). As habitats continue to

Correspondence: David D. Huff, N.O.A.A., Southwest Fisheries Science Center, Fisheries Ecology Division, 110 Shaffer Road, Santa Cruz, CA 95060, USA, Fax: 1-831-420-3921;

E-mail: david.huff@noaa.gov be degraded, there is concern that fragmented wild animal populations are vulnerable to inbreeding depression and reduced evolutionary potential (Keller \& Waller 2002; Jenkins 2003). Yet, reintroduction practices may hasten a decline in genetic variability by reducing the effective population size of the source and reintroduced populations (Lande \& Barrowclough 1987; Griffith et al. 1989; Wolf et al. 1996). Intentional hybridization of genetically divergent source populations is a reintroduction approach that may alleviate inbreeding depression (e.g., Pimm et al. 2006), restore genetic diversity to historic levels and provide novel 
genetic combinations required for rapid evolutionary change (Lewontin \& Birch 1966; Stockwell et al. 2003).

An increase in fitness known as hybrid vigour that may result from either the suppression of deleterious recessive alleles or the beneficial overdominance has been recognized as a useful application of outbreeding (or hybridization) for centuries (Darwin 1876; Lynch 1991). However, intentional mixing of distinct source populations poses risks (Lesica \& Allendorf 1999; Jones 2003); among these is a decline in fitness among offspring that are the product of mating between genetically disparate individuals, known as outbreeding depression (Lynch 1991; Tallmon et al. 2004). Two mechanisms may lead to outbreeding depression. First, interpopulation hybridization may decrease fitness because introduced nonlocal alleles cause a population to become less suited to local environmental conditions by producing intermediate phenotypes (Hatfield \& Schluter 1999). Reduced fitness by this mechanism would be apparent in the $F_{1}$ generation. Outbreeding depression may also occur by a second mechanism, the disruption of positive epistatic interactions (i.e., co-adapted gene complexes), which would only occur beyond the first generation because of recombination and segregation during meiosis in the $F_{1}$ generation. The resulting $F_{2}$ genomes may contain genes with different evolutionary histories that have not undergone co-adaptive selection as a group (Brncic 1954; Templeton et al. 1986).

Although there is debate that inbreeding depression may not be relevant to wild populations (Pusey \& Wolf 1996), there is ample evidence that it occurs (Keller \& Waller 2002). Conversely, recent literature has highlighted the potential importance of outbreeding depression for conservation, but there is a relative paucity of reports that document it (Edmands 2007; McClelland \& Naish 2007). Most outbreeding studies rely on controlled crosses conducted in a laboratory, whereas studies in natural environments are rare, especially those in wild fish populations (Edmands 2007; McClelland \& Naish 2007). While laboratory studies focus on purely genetic components that require little environmental context, field studies can provide opportunities to measure the genetic and ecological constituents of hybrid fitness acting in concert. This environment-dependent reduction in hybrid fitness is relevant to both conservation efforts and our understanding of the role of divergent evolution as the basis of local adaptation and, ultimately, reproductive isolation.

Outbreeding depression has been demonstrated in a variety of organisms, including fish (Endler 1977; Edmands 2007; McClelland \& Naish 2007). Nevertheless, a meta-analysis of the consequences of unrelated fish population crosses by McClelland \& Naish (2007) demonstrated that overall the response to outbreeding was positive and there was no relationship between the genetic distance among parental populations and its effect on life history, behavioural, morphological or physiological traits. Yet many of the comparisons they reported were inconclusive. Failure to detect positive or negative outcomes of outbreeding may have been associated with small sample sizes and a lack of power to detect statistical significance, especially in the $F_{2}$ generation. Ultimately, they concluded that outbreeding consequences may be difficult to predict and that it might be unreasonable to make broad generalizations because of the variety of processes by which an outbreeding effect may occur. They also identified several gaps in the understanding of outbreeding outcomes in fishes. Among these were documenting responses to outbreeding beyond the $F_{1}$ generation, responses of fitness related traits within a single species, the influence of environment on hybrid response and the relationship between outbreeding depression and genetic distance.

We utilized a native fish reintroduction programme that provided a unique opportunity to investigate outbreeding effects in a natural setting. The timing, number and origin of reintroduced individuals were known, the source populations were genetically distinct and there were nine discrete reintroduced populations in close geographic proximity that provided an unusual degree of replication for a field study (See Huff et al. 2010 for additional details). We recognized the potential for adaptive differences between source populations because one of the source strains was far more persistent in the reintroduced populations. We accordingly hypothesized that the fitness surrogates body size, growth rate and body condition would differ among pure strain individuals in the reintroduced populations depending on ancestral origin. Furthermore, we investigated the consequences of outbreeding on fitness surrogates in first- and second-generation hybrid crosses and backcrosses among young-of-the-year (hatched to age I) and over-yearlings (older than age I). Our aim in including second-generation crosstypes in the analysis was to enable a greater understanding of the genetic mechanisms underlying outbreeding if we detected a difference among crosstypes in fitness surrogates.

\section{Methods}

\section{Study organism and reintroduction project}

The slimy sculpin (Cottus cognatus Richardson) is a small $(<130 \mathrm{~mm})$, cryptic, freshwater fish that occupies benthic habitats in lakes, rivers and small streams from Virginia, USA, to Labrador in eastern Canada and northwest across Canada to eastern Siberia (Scott \& Crossman 1979). Cottus spp. are often locally abundant 
and are frequently a prominent constituent of ecosystems suited to trout and other cold-water fish (Petrosky \& Waters 1975; Goyke \& Hershey 1992). Slimy sculpins in the study region spawn once per year during the early spring at age II, or rarely at age I, and live up to 6 years (Petrosky \& Waters 1975).

The study area is located in the Driftless Region of south-east Minnesota, USA (Fig. 1). Prior to major settlement by European immigrants beginning in 1850, nearly all of the spring-fed streams in the region presumably held slimy sculpins and brook trout (Salvelinus fontinalis). In subsequent years, slimy sculpin and other cold-water fish abundance declined because of severe habitat degradation and overexploitation (Waters 1977; Leopold \& Sewell 2001). Since the 1940s, the Minnesota Department of Natural Resources (MNDNR) and other organizations completed hundreds of in-stream improvement projects (Waters 1977; Thorn et al. 1997; MNDNR 2003). In locations where they improved habitat sufficiently, MNDNR personnel recently reintroduced slimy sculpins. The goal was to re-establish viable, self-sustaining populations where native populations were likely present historically, but had been extirpated. Nine recipient streams were stocked from 2003 to 2005 in mid-autumn with a mixture of sculpins from three source streams. The source streams are all small tributaries in separate sub-drainages that enter the Mississippi River within approximately 40 river kilometers of each other (Fig. 1). We focus our analysis on only two of these source ancestries: Beaver Creek (Beaver) and Garvin Brook (Garvin). Although three source populations were originally reintroduced, for this evaluation, we did not consider descendents from one source, Cold Spring Brook, because initial analyses indicated very low overall ancestry in most reintroduced populations and they were not stocked some years in certain streams. A total of 1230 Beaver and Garvin sculpins were stocked in equal proportions across all nine reintroduction sites. Huff et al. (2010) provide additional details for the reintroduction programme.

\section{Sampling}

We conducted sampling in autumn 2007 at all source and recipient sites except Pickwick Creek, which we sampled in spring and autumn 2008 and autumn 2009. We additionally sampled Little Pickwick Creek in autumn 2008 and autumn 2009. We collected fish using a Wisconsin ${ }^{\mathrm{TM}}$ Abp-3 pulsed DC backpack electrofisher with power output settings adjusted to minimize effects on the reintroduced fish (Cowx \& Lamarque 1990). We anaesthetized fish with tricaine methanosulfate (MS222) (Summerfelt \& Smith 1990); then we weighed and measured standard length for each fish. We clipped a small amount of tissue from the left pelvic fin of each fish and preserved it in 95\% ethanol for genetic analysis. After processing, we returned all fish to the streams, except those captured in autumn 2008 and 2009 at Pickwick and Little Pickwick sites. We euthanized these fish with a lethal dose of anaesthetic ( $1 \mathrm{~g} / \mathrm{L}$ of MS-222) and retained them for otolith analysis. We did not capture any of the visibly marked, originally stocked fish during these sampling events.

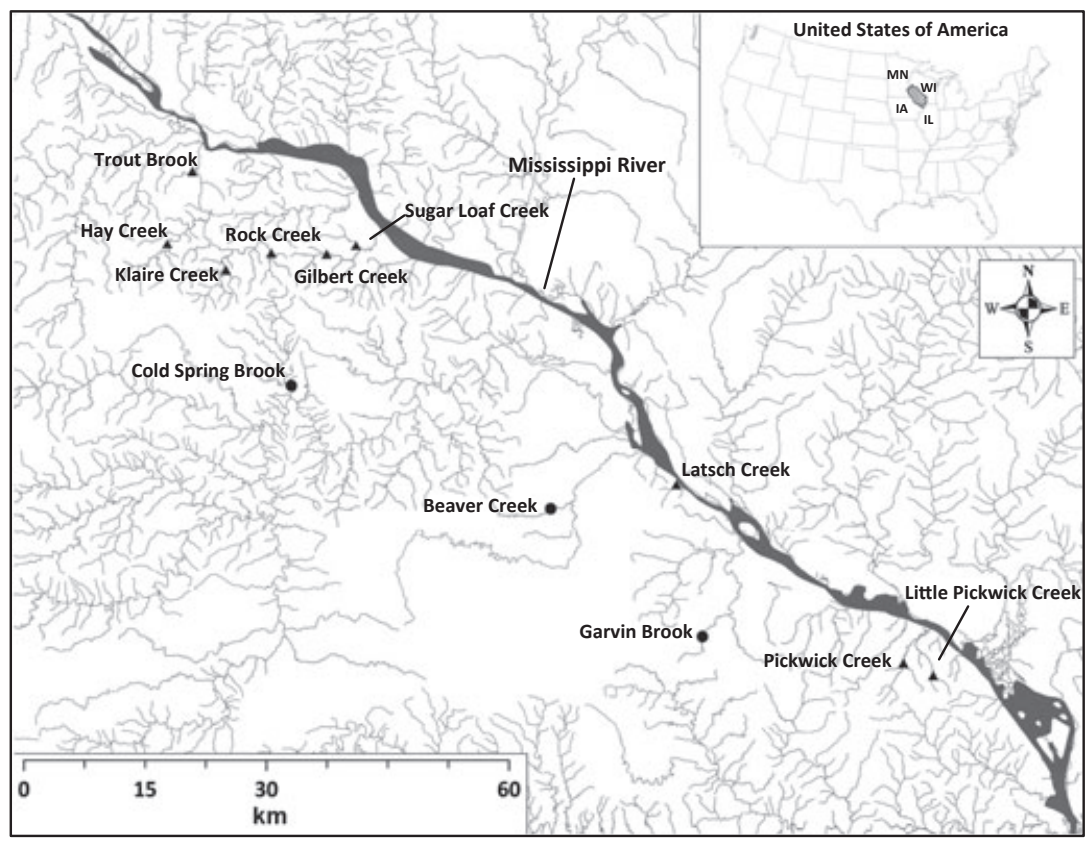

Fig. 1 Source (closed circle) and recipient (closed triangle) sites in south-east Minnesota. The Driftless Region where study sites are located is shown in the inset, indicated by the cross-hatched area covering portions of Minnesota, Wisconsin, Iowa and Illinois. 


\section{DNA extraction and amplification}

For 2007 and 2008 samples, we initially used eight microsatellite loci developed for other Cottus species that resolved genetic variation in C. cognatus: Cgo18, Cgo42, Cgo310 and Cgo1033 (Englbrecht et al. 1999); Cott290, Cott686 and CottES1 (Nolte et al. 2005); and Cba14 (Fiumera et al. 2002). We extracted DNA for polymerase chain reaction (PCR) amplification using a chelating resin as described in Fujishin et al. (2009). Microsatellite amplification was performed in $15 \mu \mathrm{L}$ reactions containing $1 \times$ polymerase buffer $(10 \mathrm{~mm}$ Tris- $\mathrm{HCl}, 50 \mathrm{~mm} \mathrm{KCl}$, $0.1 \%$ Triton $\left.^{\circledR} \mathrm{X}-100\right), 1.5 \mathrm{~mm} \mathrm{MgCl}$, $0.2 \mathrm{~mm}$ each dNTP, $0.5 \mu \mathrm{M}$ of the forward and reverse primers, with the forward primer labelled with a fluorescent dye 6FAM, VIC, NED or PET, and 0.5 units Taq DNA polymerase (Promega, Madison, WI, USA). Amplification was carried out in a thermocycler (Hybaid Omn-E; ThermoHybaid US, Franklin, MA, USA) with 35 cycles at the following temperature profile: $95{ }^{\circ} \mathrm{C}$ for $30 \mathrm{~s}, 50{ }^{\circ} \mathrm{C}$ for $30 \mathrm{~s}$ and $72{ }^{\circ} \mathrm{C}$ for $1 \mathrm{~min}$; followed by a 20-min extension at $72{ }^{\circ} \mathrm{C}$. We submitted PCR products to the Biomedical Genomics Center (University of Minnesota, St. Paul, MN, USA) for electrophoresis on an ABI Prism 3130xl Genetic Analyzer (Applied Biosystems, Foster City, CA, USA). We scored alleles using the software program GENOTYPER 2.5 (Applied Biosystems 2001). For samples that we determined to be advanced generation crosses, we carried out a second round of amplification with six newly developed microsatellite loci for C. $\operatorname{cog} n-$ atus (Fujishin et al. 2009): Cco01, Cco09, Cco10, Cco14, Cco15 and Cco17. Autumn 2009 samples from Little Pickwick Creek and Pickwick Creek were genotyped at 12 loci, with the lower variation markers Cott290 and Cott686 removed from the original set.

\section{Crosstype assignment}

We used multilocus genotype data to assign individual fish to one of six crosstypes: parental (Beaver, Garvin), first-generation hybrids $\left(F_{1}\right)$ or second-generation hybrids $\left[F_{2}\right.$, backcrosses to Beaver $\left(F_{1} \times B\right)$, or backcrosses to Garvin $\left(F_{1} \times G\right)$ ]. First, we evaluated data from three source populations in MICROCHECKER v2.2.3 to detect evidence of null alleles or scoring errors because of large allele drop-out (Van Oosterhout et al. 2004). Conformance with Hardy-Weinberg expectations and linkage equilibrium was tested using GENEPOP v4.0.4 (Raymond \& Rousset 1995). We adjusted significance values for both tests using sequential Bonferroni procedures (Rice 1989).

We next removed fish with Cold Spring ancestry from the dataset. The proportion of each individual's ancestry derived from the three source populations was estimated using the Bayesian clustering algorithm implemented in the program structure (V. 2.2.3; (Pritchard et al. 2000); also refer to http://pritch.bsd.uchicago.edu). The number of populations $(K)$ was set to three, which was the known number of genetically distinct source populations, with an admixture model and correlated allele frequencies. We ran the program with a 50000 burn-in period followed by 100000 Monte Carlo simulations. Baseline individuals were included in the runs without population identification to assist resolution of genetically differentiated clusters and determine the ability of STRUCTURE to determine the ancestry of known fish. Individuals with probable Cold Spring ancestry $(q>0.125)$ were removed from the dataset, and we conducted subsequent analyses with only Beaver Creek and Garvin Brook descendents.

The software NewHybrids (Anderson \& Thompson 2002) was used to classify individual fish to crosstypes assuming no more than second-generation descendents of founders were present. This assumption is reasonable as reintroduced populations were sampled within 3 years of initial spawning and sculpins typically mature at age 2 (Petrosky \& Waters 1975). Individuals from the two source populations were included as a baseline in the analyses. Each run had a 50000 burn-in period followed by 150000 simulations, using the Jeffreys prior option for allele frequencies and mixing proportions. Runs were repeated using different seeds to verify that consistent solutions were found. We classified individuals into a pure strain or hybrid category if their probability of membership was $\geq 0.70$; otherwise, the classification of the individual was considered uncertain. Second-generation hybrids were difficult to distinguish, so we genotyped the previously mentioned additional six loci for all individuals whose combined probability of membership across all three-second-generation cross-types exceeded 0.70 and repeated the NewHybrids analysis.

\section{Statistical analysis}

Expected quantities of each strain within the reintroduced populations were estimated for the autumn 2007 sampling season using a two-generation multinomial expansion of crosstypes based on the quantity of individuals from each strain that were stocked and assuming null conditions: equal survival, equal reproduction and random mating among lineages (see Epifanio \& Philipp 2000). The first and second generations comprised the total population in a $1: 2$ ratio, and originally stocked fish were subtracted from the totals for each corresponding pure strain category. We considered a $1: 2$ ratio a conservative approximation of overall population growth based on population estimates (Huff 
2010) that indicate abundances from 2 to 10 times greater than were originally stocked in the reintroduced populations. This ratio would also tend to overestimate expected pure strain and $F_{1}$ individuals because more of these are produced in the first generation of admixture than the second (Epifanio \& Philipp 2000). Likewise, expected quantities of $F_{2}, F_{1} \times B$ and $F_{1} \times G$ would be underestimated by our chosen ratio. Statistical assessment of the divergence between expected and observed values for each category was made using the median test (Zar 1999), a version of the Kruskal-Wallis ANOVA that frames the computation in terms of a contingency table. Pickwick and Little Pickwick populations were stocked once in autumn 2005, so there were only Beaver, Garvin and $F_{1}$ crosstypes present in 2007 and spring 2008. Our estimate, therefore, included only firstgeneration crosstypes (Beaver, Garvin, and $F_{1}$ ) for the two Pickwick sites based on the timing of the sampling relative to when these sites were stocked.

We used a fixed effects model (Weisberg 1993; Weisberg et al. 2010) to analyse differences among crosstypes in incremental growth rates using otoliths collected from 418 sculpins from Pickwick and Little Pickwick reintroduction sites. Because extracting otoliths from fish is lethal, we killed fish from only two of the populations. Otoliths were collected from these populations in autumn of 2008 and 2009 to ensure that there would be enough $F_{2}, F_{1} \times B$ and $F_{1} \times G$ crosstypes to develop a growth model. We modelled the growth increments for each fish as a function of four fixed effects: age (levels $=0,1$, and 2), stream (levels = Pickwick and Little Pickwick), crosstype (levels = Garvin, Beaver, $F_{1}, F_{2}, F_{1} \times B$ and $F_{1} \times G$ ) and sex (levels = Male, Female and Unknown). Following specifications from Weisberg et al. (2010), we also included Year, Year-Age interaction and Unique ID as random effects because of year-to-year variation likely to occur between the sequential years of sampling and natural variation likely to occur among individual fish. The Year-Age interaction was included in the model to allow for separate year effects during each year of a fish's life. Models were fit using the function lmer (Bates \& Maechler 2009) in $R$ (v 2.10.0) using maximum likelihood procedures. Starting with the full model containing all fixed parameters and 2-level interactions, we used backward model selection to select the most parsimonious model as determined by the lowest Akaike Information Criterion (AIC) corrected for sample size (Burnham \& Anderson 1998). The lmer function does not produce $\mathrm{p}$-values for model parameters so these were calculated using the pvals.fnc function in R (Baayen 2009), which computes $P$-values and Markov chain Monte Carlo (1000 iterations) confidence intervals for mixed models. Post-hoc multiple comparisons of means
(Tukey's) among crosstypes were calculated using the glht function in $R$ (Hothorn et al. 2008).

Because there are possible age differences between first (Beaver, Garvin and $\left.F_{1}\right)$ and second $\left(F_{2}, F_{1} \times B\right.$ and $\left.F_{1} \times G\right)$ generation crosstypes that could be because of differential survival or recent stocking, we categorized all fish into two age categories that included young-ofthe-year and over-yearlings. All young-of-the-year fish were designated by length $(<41 \mathrm{~mm}, n=91)$, based on age-length relationships from the Pickwick otolith data and supplementary otolith data from Beaver $(n=38)$ and Garvin ( $n=39$ ) source sites (see Appendix S1).

In addition to crosstype comparisons for weight and length, we compared relative body condition, a trait that is generally considered a good indicator of fitness in fish (Danzmann et al. 1988; Rakitin et al. 1999; Thelen \& Allendorf 2001) to corroborate potential differences in growth rate and body size. We estimated body condition by calculating relative condition factor $\left(K_{n}\right)$, which has previously been employed as a fitness related trait in Cottus species (Knaepkens et al. 2002), for each fish. Relative condition factor is defined as $K_{n}=W / W_{\text {pred }}$, where $\mathrm{W}$ is the observed weight and $W_{\text {pred }}$ is the predicted weight from a third-order polynomial based on a weight-length relationship (LeCren 1951; Wootton 1998) developed for each reintroduced population.

\section{Results}

\section{Genetic markers and error simulations}

The microsatellite data indicated strong differentiation between the source populations $\left(F_{\mathrm{ST}}=0.32, P<0.05\right)$. Within each population, all loci were in Hardy-Weinberg and linkage equilibrium. We detected no evidence for null alleles or large allele dropout. Simulated genotypes for the eight initial loci in NewHybrids estimated error rates of $2-6 \%$ for Beaver, Garvin and $F_{1}$ crosstypes; these errors caused assignment to $F_{2}, F_{1} \times B$ and $F_{1} \times G$, whereas $8-12 \%$ of $F_{2}, F_{1} \times B$ and $F_{1} \times G$ crosstypes were erroneously assigned to Beaver, Garvin and $F_{1}$ crosstypes. Simulations using all 12 loci estimated error rates of $0-0.3 \%$ for Beaver, Garvin and $F_{1}$ crosstypes. For $F_{2}, F_{1} \times B$ and $F_{1} \times G$ crosstypes, $2-5 \%$ erroneously assigned to Beaver, Garvin or $F_{1}$, and $1-3 \%$ of backcrosses erroneously assigned to $F_{2}$, while $12 \%$ of $F_{2}$ erroneously assigned to backcrosses.

\section{Persistence}

Assignment of crosstypes for 1230 slimy sculpins revealed that there were more sculpins of Beaver ancestry $(531 ; 43 \%$ of total) at the reintroduction sites than 
any other crosstype. $F_{1}$ was the next most numerous crosstype $(315 ; 26 \%$ of total), followed by Garvin (196; $16 \%$ of total). $F_{2}, F_{1} \times B$ and $F_{1} \times G$ crosstypes made up the remaining $16 \%$ (188 individuals) of the samples. Beaver individuals occurred in a significantly greater frequency than expected (Fig. 2) based on null conditions (median test; median $=31.0, \chi^{2}=5.6, \quad P=0.02$ ). All other crosstypes occurred at lower frequencies than expected, but only $F_{2}$ (median test; median $=14.4$, $\chi^{2}=7.1, \quad P=0.01$ ) and $F_{1} \times G \quad$ (median test; median $\left.=5.0, \chi^{2}=7.1, P=0.01\right)$ were significantly lower.

\section{Comparison of growth rate, weight, length and body condition}

We divided the dataset into young-of-the-year and over-yearlings to investigate fitness surrogate patterns among crosstypes at different life stages. There were 531 young-of-the-year and 699 over-yearling sculpins in the total 1230 fish sample. Figure 3 graphically compares means and 95\% confidence intervals and Table 1 summarizes $P$-values from pairwise comparisons among crosstypes (Tukey's honestly significant difference test) for all fitness surrogate models including growth rate, weight, length and body condition for both young-of-the-year and over-yearlings. With the exception of growth rate (described in the Methods), we performed a main effects analysis of variance that included crosstype and stream as factors. The pattern of differences in crosstypes among young-of-the-year fitness surrogates was generally similar. Beaver surrogates were greater than the other crosstypes, whereas secondgeneration crosstypes $\left(F_{2}, F_{1} \times B\right.$ and $\left.F_{1} \times G\right)$ were over- all lower and tended to be highly variable. Over-yearling results were comparatively consistent; however, in contrast to young-of-the-year results, Garvin fitness surrogates were superior to all other crosstypes. We did not analyse each reintroduction site individually because of the sparse distribution of some crosstypes among various sites and the concern that an uneven lack of sensitivity among the sites could produce inconclusive and potentially misleading results. A supplemental table (Appendix S2) includes mean weights, lengths and body condition values for each crosstype by reintroduction site.

The most parsimonious otolith incremental growth model for over-yearlings (Fig. 3) had the following fixed effects (ANOVA, $P<0.001$ for all variables): age $(F=23.7,3$ d.f. $)$, stream $(F=148.5,1$ d.f. $)$, sex $(F=32.3$, 2 d.f.) and crosstype ( $F=7.2,5$ d.f.). Over-yearling otolith growth in $F_{2}, F_{1} \times B$ and $F_{1} \times G$ crosstypes was lower than in Beaver, Garvin or $F_{1}$. Garvin over-yearlings grew significantly faster than Beaver, $F_{2}, F_{1} \times B$ and $F_{1} \times G$ crosstypes, and Beaver growth was only significantly faster in a pairwise comparison with $F_{1} \times B$, although Beaver also grew notably faster than $F_{2}$ (Table 1). $F_{1}$ over-yearlings grew significantly faster than $F_{2}$ and $F_{1} \times B$ crosstypes. Young-of-the-year otolith growth (Fig. 3) differed significantly (ANOVA, $P<0.05$ for all variables) among age at capture $(F=3.9,1$ d.f.), stream ( $F=40.1,2$ d.f.), crosstype $(F=11.5,5$ d.f. $)$ and sex $\left(F=7.5,2\right.$ d.f.). Otolith growth in $F_{2}, F_{1} \times B$ and $F_{1} \times G$ crosstypes was significantly lower than in Beaver, Garvin or $F_{1}$ (Table 1). However, in contrast to over-yearlings, young-of-the-year growth rates were fastest for Beaver rather than Garvin.
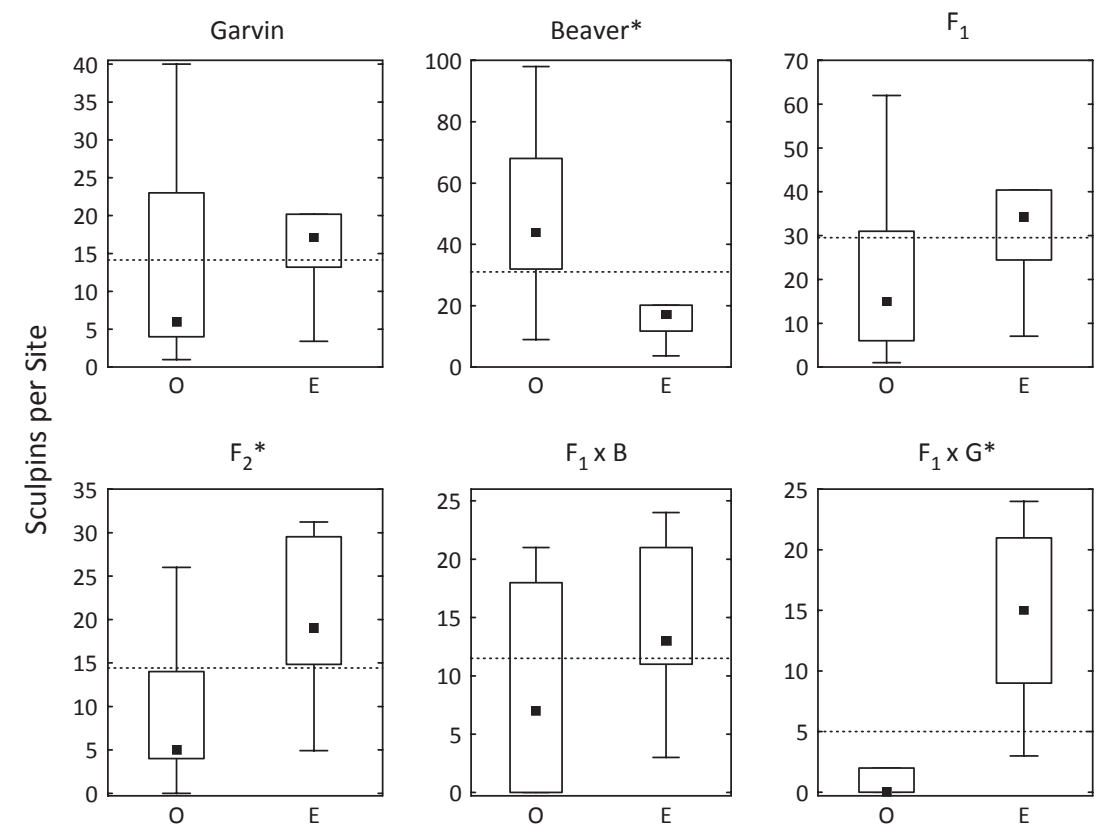

Fig. 2 Median (closed square), 1st and 3rd quartile (rectangle), and range (whisker) for observed versus expected numbers of sculpins in the reintroduced populations for each crosstype. Significant differences between observed and expected quantities $(P>0.05$, median test) are indicated with an asterisk. The dashed line in each panel represents the overall median.
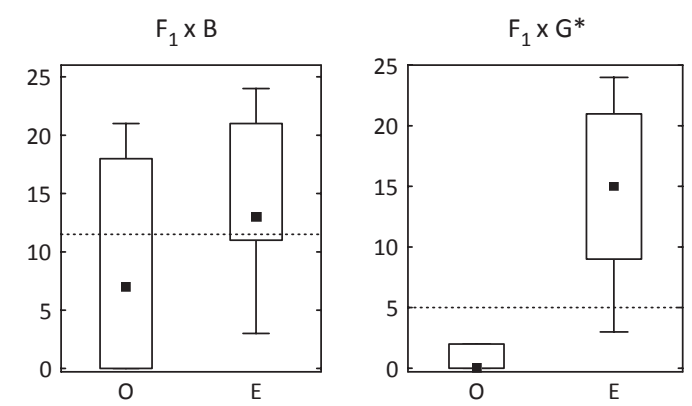

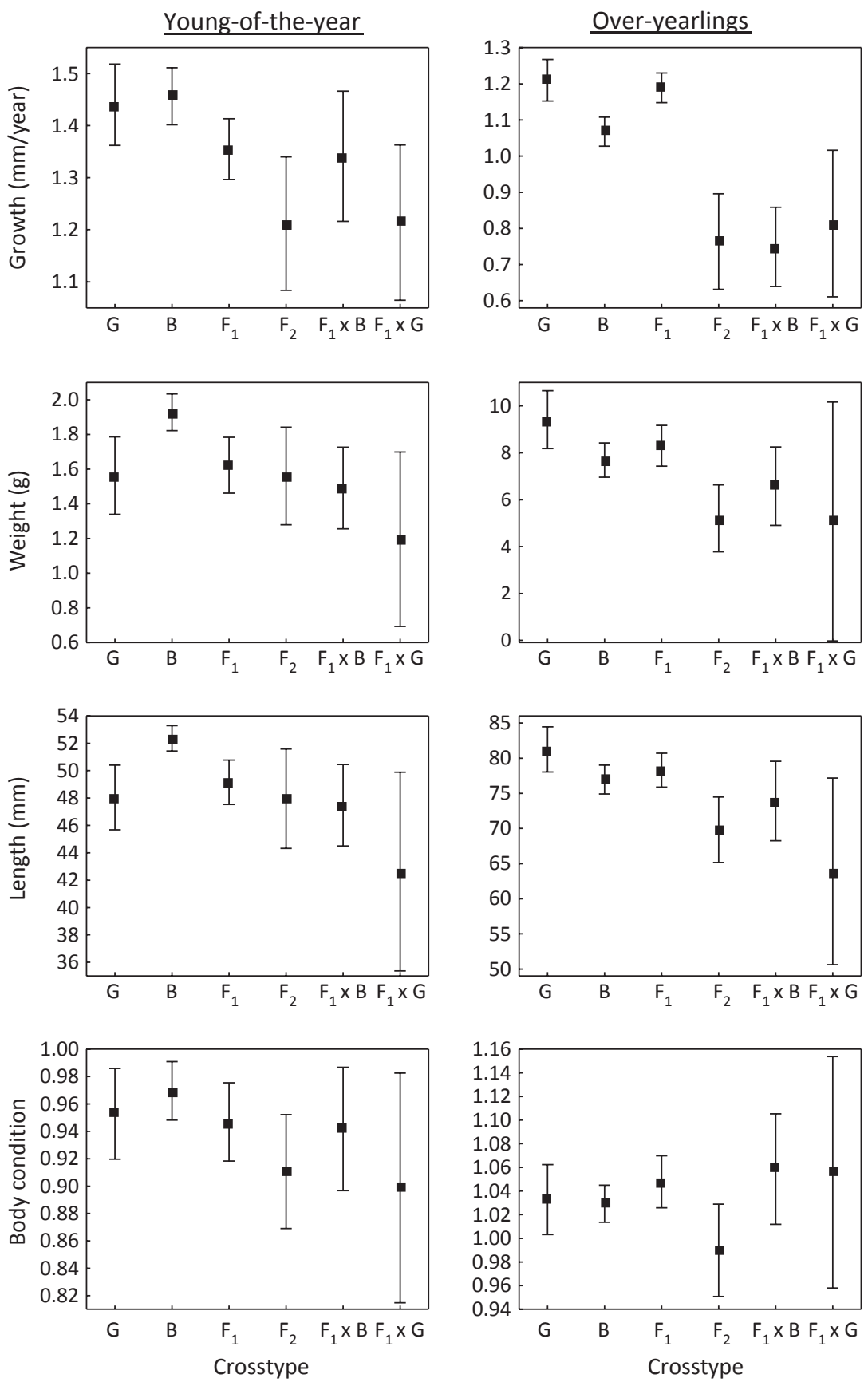

Fig. 3 Mean (closed square) and 95\% confidence intervals (whisker) for otolith growth, weight, length and body condition by crosstype for young-of-the-year (left panels) and over-yearlings (right panels). Significant pairwise comparisons are given in Table 1 . Otolith growth (top panels) was modelled with a fixed effects least-squares ANOVA using data collected at two reintroduction sites: Pickwick and Little Pickwick Creek $(n=418)$. All other values were calculated across all nine reintroduction sites $(n=1230)$.
For over-yearlings, mean weights (Fig. 3) differed by stream (ANOVA; $F=25.57,8$ d.f., $P \ll 0.001$ ) and crosstype (ANOvA; $F=11.36,5$ d.f., $P \ll 0.001$ ). Garvin was significantly heavier than Beaver and $F_{2}$ crosstypes. $F_{1}$ fish were intermediate to Garvin and Beaver, but were significantly heavier than $F_{2}$ (Table 1 ). Mean weights in $F_{2}, F_{1} \times B$ and $F_{1} \times G$ crosstypes were lower than Beaver, Garvin and $F_{1}$ crosstypes. Young-of-the-year mean weights (Fig. 3) differed significantly among streams (ANOVA; $F=31.60,5$ d.f., $P \ll 0.001$ ) and crosstype (ANOvA; $F=3.86,5$ d.f., $P=0.002$ ). Beaver was significantly heavier than all other crosstypes (Table 1).

For over-yearlings, mean lengths (Fig. 3) differed by stream (ANOVA; $F=31.76,8$ d.f., $P \ll 0.001$ ) and crosstype (ANOVA; $F=13.86,5$ d.f., $P \ll 0.001$ ). Garvin were longer than Beaver, $F_{2}$ and $F_{1} \times G$ crosstypes. $F_{1}$ fish were intermediate in length to Garvin and Beaver, but were significantly longer than $F_{2}$ and $F_{1} \times G$. Mean lengths in $F_{2}, F_{1} \times B$ and $F_{1} \times G$ crosstypes were lower than Beaver, Garvin and $F_{1}$ crosstypes (Table 1). Young-of-the-year mean lengths (Fig. 3) 
Table 1 P-Values from Tukey's honestly significant difference test among crosstypes for growth rate, weight, length and body condition. Young-of-the-year values are in the bottom diagonal, and over-yearling values are in the top diagonal. Bold $P$-values are $\leq 0.05$. ANOVA univariate tests of significance for each full model are given in the text

\begin{tabular}{|c|c|c|c|c|c|c|}
\hline Growth rate & G & $B$ & $F_{1}$ & $F_{2}$ & $F_{1} \times B$ & $F_{1} \times G$ \\
\hline$G$ & - & 0.01 & 0.23 & $<0.001$ & $<0.001$ & 0.05 \\
\hline B & 1.00 & - & 0.62 & 0.08 & 0.01 & 0.59 \\
\hline$F_{1}$ & 1.00 & 1.00 & - & 0.02 & $<0.001$ & 0.30 \\
\hline$F_{2}$ & $<0.001$ & $<0.001$ & $<0.001$ & - & 1.00 & 1.00 \\
\hline$F_{1} \times B$ & $<0.001$ & $<0.001$ & $<0.001$ & 0.89 & - & 0.99 \\
\hline$F_{1} \times G$ & $<0.001$ & $<0.001$ & $<0.001$ & 1.00 & 0.94 & - \\
\hline Weight & G & $B$ & $F_{1}$ & $F_{2}$ & $F_{1} \times B$ & $F_{1} \times G$ \\
\hline G & - & 0.04 & 0.48 & $<0.001$ & 0.12 & 0.17 \\
\hline B & $<0.001$ & - & 0.84 & 0.10 & 0.90 & 0.69 \\
\hline$F_{1}$ & 0.99 & $<0.001$ & - & 0.02 & 0.61 & 0.47 \\
\hline$F_{2}$ & 1.00 & 0.02 & 1.00 & - & 0.92 & 1.00 \\
\hline$F_{1} \times B$ & 0.99 & $<0.001$ & 0.89 & 1.00 & - & 0.98 \\
\hline$F_{1} \times G$ & 0.43 & $<0.001$ & 0.22 & 0.49 & 0.70 & - \\
\hline Length & G & $B$ & $F_{1}$ & $F_{2}$ & $F_{1} \times B$ & $F_{1} \times G$ \\
\hline$G$ & - & 0.07 & 0.50 & $<0.001$ & 0.15 & 0.01 \\
\hline B & $<0.001$ & - & 0.92 & 0.06 & 0.90 & 0.07 \\
\hline$F_{1}$ & 0.92 & $<0.001$ & - & 0.02 & 0.66 & 0.04 \\
\hline$F_{2}$ & 1.00 & $<0.001$ & 0.94 & - & 0.87 & 0.88 \\
\hline$F_{1} \times B$ & 1.00 & $<0.001$ & 0.75 & 1.00 & - & 0.45 \\
\hline$F_{1} \times G$ & 0.08 & $<0.001$ & $<0.001$ & 0.12 & 0.18 & - \\
\hline Body condition & G & $B$ & $F_{1}$ & $F_{2}$ & $F_{1} \times B$ & $F_{1} \times G$ \\
\hline G & - & 1.00 & 0.85 & 0.34 & 0.88 & 0.99 \\
\hline B & 0.97 & - & 0.49 & 0.36 & 0.77 & 0.98 \\
\hline$F_{1}$ & 1.00 & 0.79 & - & 0.05 & 1.00 & 1.00 \\
\hline$F_{2}$ & 0.71 & 0.17 & 0.77 & - & 0.14 & 0.59 \\
\hline$F_{1} \times B$ & 1.00 & 0.85 & 1.00 & 0.92 & - & 1.00 \\
\hline$F_{1} \times G$ & 0.80 & 0.47 & 0.85 & 1.00 & 0.92 & - \\
\hline
\end{tabular}

differed significantly among streams (ANOVA; $F=34.79$, 5 d.f., $P \ll 0.001$ ) and crosstype (ANOvA; $F=5.62,5$ d.f., $P \ll 0.001)$. Beaver young-of-the-year were significantly longer than all other crosstypes, and $F_{1}$ was longer than $F_{1} \times G$ (Table 1).

Mean body condition generally showed similar trends among crosstypes to the other fitness surrogates, but few pairwise comparisons were significant. For overyearlings, mean body condition (Fig. 3) differed by stream (ANOVA; $F=58.26,8$ d.f., $P \ll 0.001$ ) and crosstype (ANOva; $F=2.05,5$ d.f., $P=0.03$ ), but the only significant pairwise difference between crosstypes was that $F_{1}>F_{2}$ (Table 1). Young-of-the-year mean body condition (Fig. 3) differed significantly among streams (ANOVA; $F=5.84,5$ d.f., $P \ll 0.001$ ), but not by crosstype (ANOVA; $F=1.31,5$ d.f., $P=0.26$ ).

\section{Discussion}

A fundamental question in the fields of evolution and conservation biology is the extent to which small, subdivided populations with restricted gene flow are influenced by selective pressures and genetic drift that lead to local adaptation, and ultimately speciation (Hanski \& Gaggiotti 2004). Genetic divergence in our source populations occurs on a very small spatial scale, as has been detected elsewhere for other species (Edmands 1999; Waser et al. 2000). Species similar to the slimy sculpin, with restricted dispersal abilities (Schmetterling \& Adams 2004), strong philopatry, patchy breeding distributions, and small effective population sizes (Fiumera et al. 2002), tend to show the strongest genetic differentiation among populations. The slimy sculpin is an especially appropriate organism for studies of local adaptation, the consequences of outbreeding, and early stages of speciation because it has a very broad distribution and lives in a wide variety of habitats (Sweigart 2009). The reduced success of hybrid offspring observed in this study, potentially arising from variation in traits such as young-of-the-year body size or growth rate could result in barriers to gene flow among distinct populations. 
The source populations in our study are geographically close $(<30 \mathrm{~km}$ apart), with similar habitats. Consequently, our null hypothesis was that reintroduced Beaver and Garvin strains would occur in equal proportions, given equal fitness and random mating among lineages. However, high $F_{\mathrm{ST}}$ values indicate little gene flow between populations (Holsinger \& Weir 2009), and this is likely a long-standing condition as the populations are in separate watersheds draining into the Mississippi River, which is unsuitable habitat for slimy sculpins. Although they evolved in very similar surroundings, each strain may have developed distinct genetic mechanisms and ecological strategies for survival (Crandall et al. 2000; Rader et al. 2005). We observed that Beaver was the only crosstype that exceeded expectations for persistence; it was more numerous than other crosstypes at eight of nine sites and made up $43 \%$ of the individuals in the study. All other crosstypes were less abundant than expected, significantly so for $F_{2}$ and $F_{1} \times G$ crosstypes. These deviations from null expectations suggest both fitness differences, and possibly nonrandom mating, among crosstypes at the reintroduction sites (Huff et al. 2010). Differential initial fitness at the reintroduction sites between Beaver and Garvin could plausibly explain low proportions of hybrid crosstypes $\left(F_{1}, F_{2}, F_{1} \times B\right.$ and $\left.F_{1} \times G\right)$. For example, if Beaver sculpins had higher survival over the first winter after stocking before spawning in the spring, fewer Garvin, and therefore $F_{1}$, would be present in the first generation of offspring. A similar outcome is possible given differential initial reproductive success. Therefore, although depressed hybrid fitness could have contributed to the observed patterns in crosstype persistence, lower than expected quantities of hybrids does not, by itself, provide conclusive evidence of reduced hybrid fitness. However, greater Beaver persistence is consistent with the hypothesis that it had higher fitness than Garvin in reintroduced populations.

Our results for over-yearlings, that Garvin are larger and grow faster, seem inconsistent with the pattern of greater Beaver persistence in the reintroduced populations, as growth rate and body size are commonly assumed to have a strong relationship to fitness in fish (Petty \& Grossman 2004; McClelland \& Naish 2007). Greater size or growth rate for Garvin and $F_{1}$ over-yearlings could result from reduced survival of smaller or slower growing young-of-the-year individuals that leave behind mostly faster growing over-yearlings. Despite the potential for reduced early survival, a high overall body condition in surviving Garvin and $F_{1}$ crosstypes may facilitate subsequent generations of crosses back to the more persistent Beaver. If selection against hybrid genotypes was not strong enough, then introgression would continue until a hybrid swarm developed and the pure strain genotype was lost (Epifanio \& Philipp 2000; Allendorf et al. 2001). Our work indicated that outbreeding studies should include as much of the life cycle as possible because the ontogenetic timing of outbreeding effects may differ greatly (McGinnity et al. 2003; Edmands 2007). A greater young-of-the-year size, and perhaps a faster growth rate, in Beaver vs. Garvin and $F_{1}$ may confer a selective advantage on Beaver at most reintroduction sites. However, growth rate differences during the first year of life may not be the only explanation for larger body size in Beaver. For example, if Beaver $\times$ Beaver mating occurred earlier or in better locations, then offspring may have more time or better conditions under which to grow. Additional studies regarding the timing and location of spawning and growth data could support different interpretations of our results.

Our analysis of fitness surrogates suggested potential mechanisms that may explain why Beaver was more persistent than Garvin in the reintroduced populations. The early survival of fishes is often strongly affected by size (Miller et al. 1988; Houde 1989). A size advantage in Beaver young-of-the-year is a consistent explanation for persistence differences between these two strains in the reintroduced populations. An ecological condition that may promote differential size and growth in young-of-the-year sculpins in our study sites is groundwater-mediated growing season length (Huff 2010). Temperature-dependent divergent life history strategies have been documented for a closely related species, Cottus gobio in which growth rates of young vs. older sculpins responded differently depending on the thermal regime of the local population (Abdoli et al. 2007). Sculpins in Garvin Brook may experience a longer growing season owing to warmer winter temperatures because streams such as Garvin Brook, with greater groundwater input (Huff 2010), will tend to remain relatively warmer in the winter and tend to cool more slowly in the autumn. Beaver Creek was more similar to most reintroduction streams in that there was comparatively less groundwater input than in Garvin; therefore, these sculpins experienced a shorter growth season, a colder winter and a warmer summer. Because of differences in temperature regimes between source streams, attainment of a larger size by the end of summer may have been more important for sculpin survival in Beaver Creek than in Garvin Brook. Size selective mortality in the first winter may enhance the fitness of faster growing sculpins that have shorter growing seasons. This has been observed among many species and has been shown to be a factor in year-class strength in fish (Shuter et al. 1980; Henderson et al. 1988; Hurst 2007), including a sculpin species (Rashleigh \& Grossman 2005). Slower young-of-the-year growth rate for fish in 
Garvin Brook would be consistent with a hypothesis in which slower growth rate phenotypes provide an advantage (Conover 1990) perhaps because of inferior swimming ability in larger fish (Billerbeck et al. 2000), increased susceptibility to predation (Lankford et al. 2001), or the costs of growth combined with the consumption of larger meals at an early life stage (Munch \& Conover 2003). Variations in winter temperatures between the source streams may cause divergent selective pressures on metabolic rates and physiological functions, swimming performance and growth (Fry 1970; Wootton 1998). Subsequently, variations and relative stability in temperature and other environmental features among the reintroduction sites may have been, overall, more favourable for sculpins adapted to conditions in Beaver Creek vs. conditions in Garvin Brook. However, environmental variations at some sites may favour, to a greater or lesser degree, sculpins adapted to conditions that are more similar to those in Garvin Brook. This could account for the high degree of variation in fitness surrogate values among streams between Garvin and Beaver sculpins.

Fitness surrogate data are consistent with the hypothesis that outbreeding depression contributed to the deficit of hybrid crosstypes. Our nine reintroduction sites represent multiple common garden experiments in which there is a significant genetically based fitness surrogate depression in $F_{1} \times B, F_{1} \times G$ and especially $F_{2}$ crosstypes. This pattern among crosstypes is consistent with disruption of advantageous co-adapted gene complexes in the second generation of hybrid crosstypes. In comparisons of growth, size or body condition, the $F_{2}$ crosstype was significantly lower than parental types or $F_{1}$. There was a greater degree of variability within the $F_{1} \times B$ and $F_{1} \times G$ crosstypes, but these crosstypes exhibited a similar pattern in fitness surrogates to $F_{2}$. Additional variability could be due in part to the potential for backcrosses to regress toward the parental condition through restored epistatic interactions (Ellison \& Burton 2008). This regression was conceivable for $F_{1} \times B$, in which we observed a slight to moderate increase in growth, and body condition relative to $F_{2}$. Fewer $F_{1} \times G$ fish may explain, at least partially, their additional variability in body condition.

Classification errors were unlikely to alter our major interpretations and conclusions. The strong differentiation among source populations provided sufficient power to distinguish crosstypes. Simulations indicated potential bias toward increased estimates of Beaver, Garvin and $F_{1}$ crosstypes, but this is contrary to our observations of fewer than expected Garvin and $F_{1}$ crosstypes. The $F_{2}$ crosstype may have been underestimated because it had the highest error rates, but most erroneously assigned to backcrosses, which also had fewer observed than expected (significantly for $F_{1} \times G$ ). Furthermore, classification error would have obscured differences in fitness surrogates among crosstypes resulting in underestimation of true differences.

Field transplant studies such as this provide advantages such as establishing the importance and magnitude of ecological barriers to gene flow (Noor \& Feder 2006) and may be of greater relevance to specific conservation scenarios. However, our study has limitations in that we used previously reintroduced populations that were not originally intended for an outbreeding study. As such were not able to choose the reintroduction locations or proportions of individuals stocked. Therefore, we urge caution when interpreting the broader implications of our results, especially considering that potential outbreeding consequences may be difficult to generalize given the variety of mechanisms that may cause them. Laboratory research with fruit flies suggests that in the long term, outbreeding depression is a temporary phenomenon and may disappear if the population can survive the initial reduced fitness (Annest \& Templeton 1978; Templeton 1986). Moreover, populations that have recently fragmented because of anthropogenic causes are less likely to experience outbreeding depression relative to populations with little historical gene flow. A worldwide decline of some animals has led conservationists to advocate increasing genetic diversity in declining, isolated populations through translocations of genetically disparate individuals (Wolf et al. 1996; Fischer \& Lindenmayer 2000). A perception that hybrid vigour is a common phenomenon (Rhymer \& Simberloff 1996), and a pervasive 'small population' paradigm (Caughley 1994), in which inbreeding depression is the major concern, may lead conservation managers to conclude that intentionally mixing source populations should be the default option in the absence of information that would indicate an alternative course of action. However, outbreeding depression may occur as frequently as hybrid vigour, and there is very little quantitative data to support assumptions otherwise (Edmands 2007). Therefore, a precautionary approach should include careful consideration of the risks associated with crossing genetically divergent sources. For populations that are already small, especially if they reproduce slowly, a short-term fitness reduction may be an unnecessary risk and could produce negative consequences.

\section{Acknowledgements}

We would like to thank Ray Newman, Eric Merten, Karen Oberhauser, Andrew Simons and three anonymous reviewers for helpful comments on the manuscript. We also thank Jason Breeggemann for assistance with otolith analysis, and Lorissa Fujishin and Keith Barker for microsatellite marker develop- 
ment. Thanks also to Vaughn Snook and Minnesota Department of Natural Resources personnel for providing technical support and resources for the project. Funding was provided by a fellowship from Austen Cargill II; a doctoral dissertation fellowship by the Graduate School of the University of Minnesota; and the Minnesota Department of Natural Resources, U.S. Geological Survey Cooperative Research Units Program. The Minnesota Cooperative Fish and Wildlife Research Unit is jointly sponsored by the U.S. Geological Survey, University of Minnesota, Minnesota Department of Natural Resources, and Wildlife Management Institute. Any use of trade, product or firm names is for descriptive purposes only and does not imply endorsement by the U.S. Government.

\section{References}

Abdoli A, Pont D, Sagnes P (2007) Intrabasin variations in age and growth of bullhead: the effects of temperature. Journal of Fish Biology, 70, 1224-1238.

Allendorf FW, Leary RF, Spruell P, Wenburg JK (2001) The problems with hybrids: setting conservation guidelines. Trends in Ecology \& Evolution, 16, 613-622.

Anderson EC, Thompson EA (2002) A model-based method for identifying species hybrids using multilocus genetic data. Genetics, 160, 1217-1229.

Annest JL, Templeton AR (1978) Genetic-recombination and clonal selection in drosophila-mercatorum. Genetics, 89, 193210.

Applied Biosystems (2001) ABI PRISM ${ }^{\circledR}$ Genotyper $^{\circledR} 2.5$ Software. Applied Biosystems, Foster City, California.

Baayen RH (2009) Analyzing linguistic data: a practical introduction to statistics. In: R Package.

Bates D, Maechler M (2009) lme4: linear mixed-effects models using $\mathrm{S} 4$ classes. In: R package.

Billerbeck JM, Schultz ET, Conover DO (2000) Adaptive variation in energy acquisition and allocation among latitudinal populations of the Atlantic silverside. Oecologia, 122, 210-219.

Brncic D (1954) Heterosis and the integration of the genotype in geographic populations of drosophila pseudoobscura. Genetics, 39, 77-88.

Burnham KP, Anderson DR (1998) Model Selection and Inference: A Practical Information-Theoretic Approach. Springer, New York.

Caughley G (1994) Directions in conservation biology. Journal of Animal Ecology, 63, 215-244.

Conover DO (1990) The relationship between capacity for growth and length of growing-season - evidence for and implications of countergradient variation. Transactions of the American Fisheries Society, 119, 416-430.

Cowx IG, Lamarque P (1990) Fishing with Electricity: Applications in Freshwater Fisheries Management. Fishing News Books, Oxford.

Crandall KA, Bininda-Emonds ORP, Mace GM, Wayne RK (2000) Considering evolutionary processes in conservation biology. Trends in Ecology \& Evolution, 15, 290-295.

Danzmann RG, Ferguson MM, Allendorf FW (1988) Heterozygosity and components of fitness in a strain of rainbow-trout. Biological Journal of the Linnean Society, 33, 285-304.
Darwin C (1876) The Effects of Cross and Self Fertilisation in the Vegetable Kingdom. J. Murray, London.

Edmands S (1999) Heterosis and outbreeding depression in interpopulation crosses spanning a wide range of divergence. Evolution, 53, 1757-1768.

Edmands S (2007) Between a rock and a hard place: evaluating the relative risks of inbreeding and outbreeding for conservation and management. Molecular Ecology, 16, 463-475.

Ellison CK, Burton RS (2008) Interpopulation hybrid breakdown maps to the mitochondrial genome. Evolution, 62, 631-638.

Endler JA (1977) Geographic Variation, Speciation, and Clines. Princeton University Press, Princeton, New Jersy.

Englbrecht CC, Largiader CR, Hanfling B, Tautz D (1999) Isolation and characterization of polymorphic microsatellite loci in the European bullhead Cottus gobio L-(Osteichthyes) and their applicability to related taxa. Molecular Ecology, 8, 1966-1969.

Epifanio J, Philipp D (2000) Simulating the extinction of parental lineages from introgressive hybridization: the effects of fitness, initial proportions of parental taxa, and mate choice. Reviews in Fish Biology and Fisheries, 10, 339-354.

Fischer J, Lindenmayer DB (2000) An assessment of the published results of animal relocations. Biological Conservation, 96, 1-11.

Fiumera AC, Porter BA, Grossman GD, Avise JC (2002) Intensive genetic assessment of the mating system and reproductive success in a semi-closed population of the mottled sculpin, Cottus bairdi. Molecular Ecology, 11, 23672377.

Fry FEJ (1970) Effects of environmetal factors. In: Fish Physiology (eds Hoar WS, Randall DJ). pp. 1-98, Academic Press, New York, London.

Fujishin LM, Barker FK, Huff DD, Miller LM (2009) Isolation of 13 polymorphic microsatellite loci for slimy sculpin (Cottus cognatus). Conservation Genetics Resources, 1, 429-432.

George AL, Kuhajda BR, Williams JD et al. (2009) Guidelines for propagation and translocation for freshwater fish conservation. Fisheries, 34, 529-545.

Goyke AP, Hershey AE (1992) Effects of fish predation on larval chironomid (Diptera, Chironomidae) communities in an Arctic ecosystem. Hydrobiologia, 240, 203-211.

Griffith B, Scott JM, Carpenter JW, Reed C (1989) Translocation as a species conservation tool - status and strategy. Science, 245, 477-480.

Hanski I, Gaggiotti OE (2004) Ecology, Genetics, and Evolution of Metapopulations. Elsevier, Burlington, Massachusetts.

Hatfield T, Schluter D (1999) Ecological speciation in sticklebacks: environment-dependent hybrid fitness. Evolution, 53, 866-873.

Henderson PA, Holmes RHA, Bamber RN (1988) Size-selective overwintering mortality in the sand smelt, Atherina boyeri Risso, and its role in population regulation. Journal of Fish Biology, 33, 221-233.

Holsinger KE, Weir BS (2009) Fundamental concepts in genetics: genetics in geographically structured populations: defining, estimating and interpreting F-ST. Nature Reviews Genetics, 10, 639-650.

Hothorn T, Bretz F, Westfall P (2008) Simultaneous inference in general parametric models. Biometrical Journal, 50, 346-363. 
Houde ED (1989) Subtleties and episodes in the early life of fishes. Journal of Freshwater Biology, 35(Suppl. A), 29-38.

Huff DD (2010) Examining genetic diversity, hybrid fitness, and local adaptation in a native fish reintroduction program, Dissertation. University of Minnesota, Minneapolis.

Huff DD, Miller LM, Vondracek B (2010) Patterns of ancestry and genetic diversity in reintroduced populations of the slimy sculpin: implications for conservation. Conservation Genetics, 11, 2379-2391.

Hurst TP (2007) Causes and consequences of winter mortality in fishes. Journal of Fish Biology, 71, 315-345.

IUCN (1998) IUCN Guidelines for Re-introductions. IUCN, Gland \& Cambridge.

Jenkins M (2003) Prospects for biodiversity. Science, 302, 11751177.

Jones TA (2003) The restoration gene pool concept: beyond the native versus non-native debate. Restoration Ecology, 11, 281290.

Keller LF, Waller DM (2002) Inbreeding effects in wild populations. Trends in Ecology \& Evolution, 17, 230-241.

Knaepkens G, Knapen D, Bervoets L et al. (2002) Genetic diversity and condition factor: a significant relationship in Flemish but not in German populations of the European bullhead (Cottus gobio L.). Heredity, 89, 280-287.

Lande R, Barrowclough GF (1987) Effective population size, genetic variation, and their use in population management. In: Viable Populations for Conservation (ed. Soule ME). pp. 87124, Cambridge University Press, Cambridge, UK.

Lankford TE, Billerbeck JM, Conover DO (2001) Evolution of intrinsic growth and energy acquisition rates. II. Trade-offs with vulnerability to predation in Menidia menidia. Evolution, 55, 1873-1881.

LeCren ED (1951) The length-weight relationship and seasonal cycle in gonad weight and condition in the perch (Perca fluviatilis). Journal of Animal Ecology, 20, 210-219.

Leopold A, Sewell M (2001) A Sand County Almanac: With Essays on Conservation. Oxford University Press, New York.

Lesica P, Allendorf FW (1999) Ecological genetics and the restoration of plant communities: mix or match? Restoration Ecology, 7, 42-50.

Lewontin RC, Birch LC (1966) Hybridization as a source of variation for adaptation to new environments. Evolution, 20, 315-336.

Lynch M (1991) The genetic interpretation of inbreeding depression and outbreeding depression. Evolution, 45, 622-629.

McClelland EK, Naish KA (2007) What is the fitness outcome of crossing unrelated fish populations? A meta-analysis and an evaluation of future research directions. Conservation Genetics, 8, 397-416.

McGinnity P, Prodohl P, Ferguson K et al. (2003) Fitness reduction and potential extinction of wild populations of Atlantic salmon, Salmo salar, as a result of interactions with escaped farm salmon. Proceedings of the Royal Society of London Series B-Biological Sciences, 270, 2443-2450.

Miller TJ, Crowder LB, Rice JA, Marschall EA (1988) Larval size and recruitment mechanisms in fishes - toward a conceptual-framework. Canadian Journal of Fisheries and Aquatic Sciences, 45, 1657-1670.

MNDNR (2003) Strategic Plan for Coldwater Fisheries Management in Southeast Minnesota, 2004-2015. Minnesota Department of Natural Resources, St. Paul, Minnesota, 1-35.
Munch SB, Conover DO (2003) Rapid growth results in increased susceptibility to predation in Menidia menidia. Evolution, 57, 2119-2127.

Nolte AW, Stemshorn KC, Tautz D (2005) Direct cloning of microsatellite loci from Cottus gobio through a simplified enrichment procedure. Molecular Ecology Notes, 5, 628-636.

Noor MAF, Feder JL (2006) Speciation genetics: evolving approaches. Nature Reviews Genetics, 7, 851-861.

Petrosky CE, Waters TF (1975) Annual production by slimy sculpin population in a small Minnesota trout stream. Transactions of the American Fisheries Society, 104, 237-244.

Petty JT, Grossman GD (2004) Restricted movement by mottled sculpin (pisces : cottidae) in a southern Appalachian stream. Freshwater Biology, 49, 631-645.

Pimm SL, Dollar L, Bass OL (2006) The genetic rescue of the Florida panther. Animal Conservation, 9, 115-122.

Pritchard JK, Stephens M, Donnelly P (2000) Inference of population structure using multilocus genotype data. Genetics, 155, 945-959.

Pusey A, Wolf M (1996) Inbreeding avoidance in animals. Trends in Ecology \& Evolution, 11, 201-206.

Rader RB, Belk MC, Shiozawa DK, Crandall KA (2005) Empirical tests for ecological exchangeability. Animal Conservation, 8, 239-247.

Rakitin A, Ferguson MM, Trippel EA (1999) Sperm competition and fertilization success in Atlantic cod (Gadus morhua): effect of sire size and condition factor on gamete quality. Canadian Journal of Fisheries and Aquatic Sciences, 56, 2315-2323.

Rashleigh B, Grossman GD (2005) An individual-based simulation model for mottled sculpin (Cottus bairdi) in a southern Appalachian stream. Ecological Modelling, 187, 247-258.

Raymond M, Rousset F (1995) An exact test for population differentiation. Evolution, 49, 1280-1283.

Rhymer JM, Simberloff D (1996) Extinction by hybridization and introgression. Annual Review of Ecology and Systematics, 27, 83-109.

Rice WR (1989) Analyzing tables of statistical tests. Evolution, 43, 223-225.

Schmetterling DA, Adams SB (2004) Summer movements within the fish community of a small Montane stream. North American Journal of Fisheries Management, 24, 11631172.

Scott WB, Crossman EJ (1979) Freshwater Fishes of Canada. Fisheries Research Board of Canada, Ottawa.

Seddon PJ, Armstrong DP, Maloney RF (2007) Developing the science of reintroduction biology. Conservation Biology, 21, 303-312.

Shuter BJ, Maclean JA, Fry FEJ, Regier HA (1980) Stochastic simulation of temperature effects on 1st-year survival of smallmouth bass. Transactions of the American Fisheries Society, $109,1-34$.

Stockwell CA, Hendry AP, Kinnison MT (2003) Contemporary evolution meets conservation biology. Trends in Ecology $\mathcal{E}$ Evolution, 18, 94-101.

Summerfelt RC, Smith LS (1990) Anesthesia, surgery and related techniques. In: Methods for Fish Biology (eds Schreck CB, Moyle PB). pp. 213-272, American Fisheries Society, Bethesda, Maryland. 
Sweigart A (2009) Sculpin hybrid zones: natural laboratories for the early stages of speciation. Molecular Ecology, 18, 2547-2548.

Tallmon DA, Luikart G, Waples RS (2004) The alluring simplicity and complex reality of genetic rescue. Trends in Ecology \& Evolution, 19, 489-496.

Templeton AR (1986) Coadaptation and outbreeding depression. In: Conservation Biology: The Science of Scarcity and Diversity (ed Soulé ME). pp. 105-116, Sinauer Associates, Sunderland, Mass.

Templeton AR, Hemmer H, Mace G et al. (1986) Local adaptation, coadaptation, and population-boundaries. Zoo Biology, 5, 115-125.

Thelen GC, Allendorf FW (2001) Heterozygosity-fitness correlations in rainbow trout: effects of allozyme loci or associative overdominance? Evolution, 55, 1180-1187.

Thorn WC, Anderson CS, Lorenzen WE, Hendickson DL, Wagner JW (1997) A review of trout management in southeast Minnesota streams. North American Journal of Fisheries Management, 17, 860-872.

Van Oosterhout C, Hutchinson WF, Wills DPM, Shipley P (2004) MICRO-CHECKER: software for identifying and correcting genotyping errors in microsatellite data. Molecular Ecology Notes, 4, 535-538.

Waser NM, Price MV, Shaw RG (2000) Outbreeding depression varies among cohorts of Ipomopsis aggregata planted in nature. Evolution, 54, 485-491.

Waters TF (1977) The Streams and Rivers of Minnesota. University of Minnesota Press, Minneapolis.

Weisberg S (1993) Using hard-part increment data to estimate age and environmental-effects. Canadian Journal of Fisheries and Aquatic Sciences, 50, 1229-1237.

Weisberg S, Spangler G, Richmond L (2010) Mixed effects models for fish growth. Canadian Journal of Fisheries and Aquatic Sciences, 67, 269-277.

Williams JE, Sada DW, Williams CD (1988) American Fisheries Society guidelines for introductions of threatened and endangered fishes. Fisheries, 13, 5-11.

Wolf CM, Griffith B, Reed C, Temple SA (1996) Avian and mammalian translocations: update and reanalysis of 1987 survey data. Conservation Biology, 10, 1142-1154.

Wootton RJ (1998) Growth. In:Ecology of Teleost Fishes (ed Wootton RJ). pp. 107-140, Kluwer Academic Publishers, New York City, New York.

Zar JH (1999) Biostatistical Analysis, 4th edn. Prentice Hall, Upper Saddle River, New Jersey.
D.H. is currently a research scholar at the University of California, Santa Cruz working with the NOAA Fisheries Ecology Division. David's research interests include autecological habitat models; community composition models; physical habitat influences on fish behaviour and distribution in freshwater and marine systems; and aspects of reintroduction biology, such as local adaptation, outbreeding depression and genetic diversity. Loren Miller is a Senior Research Associate in the Department of Fisheries, Wildlife \& Conservation Biology at the University of Minnesota. Loren is interested in the management applications for the conservation and population genetics of fish. C.C. is a research scientist at the University of Nebraska. Chris studies fisheries management, especially as it pertains to invasive species biology. B.V. is an adjunct professor at the University of Minnesota with the USGS Cooperative Fisheries and Wildlife Research Unit. Bruce's work focuses on how fish and invertebrate assemblages respond to anthropogenic disturbance.

\section{Data accessibility}

Individual microsatellite, ancestry estimates and weight-length data used in this study are available from the Dryad data repository, DOI: 10.5061/dryad.pf318.

\section{Supporting information}

Additional supporting information may be found in the online version of this article.

Appendix S1 Age distribution by length for otolith data $(n=495)$ and variance plots of raw length data at all nine reintroduction sites $(n=1230)$ grouped by crosstype.

Appendix S2 Number $(N)$ and mean weight $(W)$, length $(L)$, and body condition (BC) by crosstype for each reintroduction site by young-of-the-year (YoY) and over-yearlings (O-Y).

Please note: Wiley-Blackwell are not responsible for the content or functionality of any supporting information supplied by the authors. Any queries (other than missing material) should be directed to the corresponding author for the article. 